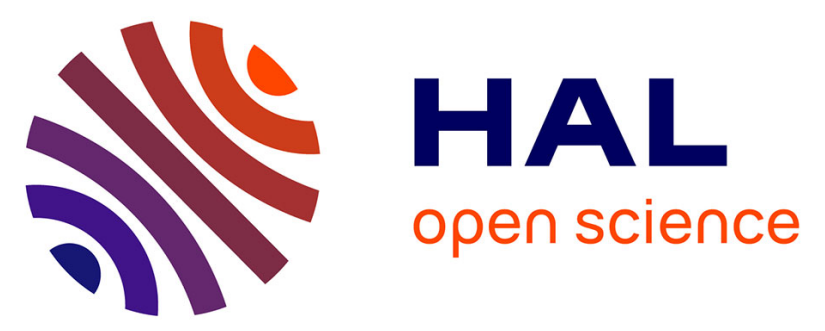

\title{
Molecular identification of three Arabidopsis thaliana mitochondrial dicarboxylate carrier isoforms: organ distribution, bacterial expression, reconstitution into liposomes and functional characterization
}

Luigi Palmieri, Nathalie Picault, Roberto Arrigoni, Evelyne Besin, Ferdinando Palmieri, Michael Hodges

\section{To cite this version:}

Luigi Palmieri, Nathalie Picault, Roberto Arrigoni, Evelyne Besin, Ferdinando Palmieri, et al.. Molecular identification of three Arabidopsis thaliana mitochondrial dicarboxylate carrier isoforms: organ distribution, bacterial expression, reconstitution into liposomes and functional characterization. Biochemical Journal, 2008, 410 (3), pp.621-629. 10.1042/BJ20070867 . hal-00478839

\author{
HAL Id: hal-00478839 \\ https://hal.science/hal-00478839
}

Submitted on 30 Apr 2010

HAL is a multi-disciplinary open access archive for the deposit and dissemination of scientific research documents, whether they are published or not. The documents may come from teaching and research institutions in France or abroad, or from public or private research centers.
L'archive ouverte pluridisciplinaire HAL, est destinée au dépôt et à la diffusion de documents scientifiques de niveau recherche, publiés ou non, émanant des établissements d'enseignement et de recherche français ou étrangers, des laboratoires publics ou privés. 
Molecular identification of three Arabidopsis thaliana mitochondrial dicarboxylate carrier isoforms: organ distribution, bacterial expression, reconstitution into liposomes and functional characterization

Luigi Palmieri" ${ }^{*}$, , Nathalie Picault ${ }^{\mathbb{1},+}$, Roberto Arrigoni ${ }^{*}$, , Evelyne Besin, Ferdinando Palmieri ${ }^{*} \S, 1$ and Michael Hodges

*Department of Pharmaco-Biology, Laboratory of Biochemistry and Molecular Biology, University of Bari, Via Orabona 4, 70125 Bari, Italy

${ }^{\S} \mathrm{CNR}$ Institute of Biomembranes and Bioenergetics, Via Orabona 4, 70125 Bari, Italy "Institut de Biotechnologie des Plantes, CNRS UMR8618, Bâtiment 630, Université de Paris Sud 11, 91405 Orsay, Cedex, France.

${ }^{+}$Present address : Laboratoire Génome et Développement des Plantes, UMR 5096 CNRSIRD, Université de Perpignan, Perpignan 66860, France.

Short page heading: Arabidopsis mitochondrial dicarboxylate carriers

${ }^{1}$ To whom correspondence should be addressed (email fpalm@farmbiol.uniba.it)

Footnote: Sequence data reported in this paper as DIC1, DIC2 and DIC3 have been deposited in the EMBL Data Bank with accession numbers AM236862, AM236863 and AM236861, respectively.

Abbreviations used: EST, expressed sequence tag; DIC, dicarboxylate carrier; DTC, di-/tricarboxylate carrier; MCF, mitochondrial carrier family; PUMP, uncoupling protein 
Screening of the Arabidopsis thaliana genome revealed three potential homologs of mammalian and yeast mitochondrial dicarboxylate carriers designated as DIC1, DIC2 and DIC3, each belonging to the mitochondrial carrier protein family. DIC1 and DIC2 are broadly expressed at comparable levels in all the tissues investigated. DICs 1-3 have been reported previously as uncoupling proteins, but direct transport assays with recombinant and reconstituted DIC proteins clearly demonstrate that their substrate specificity is unique to plants, showing the combined characteristics of the dicarboxylate carrier and oxaloacetate carrier in yeast. Indeed, the Arabidopsis DICs transported a wide-range of dicarboxylic acids including malate, oxaloacetate and succinate as well as phosphate, sulphate and thiosulphate at high rates, whereas 2-oxoglutarate revealed to be a very poor substrate. The role of these plant mitochondrial dicarboxylate carriers is discussed with respect to other known mitochondrial carrier family members including uncoupling proteins. It is proposed that plant DICs constitute the membrane component of several metabolic processes including the malate-oxaloacetate shuttle, the most important redox connection between mitochondria and the cytosol.

Key words: Arabidopsis thaliana, dicarboxylate carrier, functional reconstitution, mitochondria, mitochondrial carrier family, transport 


\section{INTRODUCTION}

In addition to respiration and cellular energy supply, plant mitochondria fulfil a range of metabolic tasks, some of which are essential to several plant-specific processes such as photorespiration, C4 and crassulacean acid metabolism photosynthesis, the utilization of carbon, nitrogen and lipid storage compounds during seed germination and the $\gamma$-aminobutyric acid shunt. Because individual steps in these metabolic pathways are carried out in different cell compartments, there is a continuous need to move metabolites, nucleotides, and cofactors into and out of mitochondria.

The transport of solutes across the inner mitochondrial membrane is achieved by a number of proteins that belong to the mitochondrial carrier family (MCF) [1-5]. Family members have a tripartite structure consisting of three tandemly repeated sequences of about 100 amino acids in length. Each repeat contains 2 hydrophobic stretches that span the membrane as $\alpha$-helices and a characteristic sequence motif. The yeast genome encodes 35 MCF members [6,7] and the human genome at least 50 [2]. An analysis of the Arabidopsis thaliana genome has led to the identification of 58 possible MCF members [4]. Thus far, several plant mitochondrial carriers have been identified by their high similarity with orthologs in other organisms [8-10], their transport properties upon heterologous expression and reconstitution into liposomes [11-15] and by functional complementation of yeast mutants $[13,16,17]$. However, many other transport activities observed in plant mitochondria and/or liposomes reconstituted with plant proteins of varying purity await to be associated with specific protein sequences. An example is the dicarboxylate carrier (DIC), which catalyzes the transport of dicarboxylates (malate and succinate) in exchange for phosphate, sulfate or thiosulfate [18]. In mammals, the DIC plays an important role in gluconeogenesis, urea synthesis and sulphur metabolism especially in the liver [19], whereas in yeast it is believed to have an anaplerotic function [20]. In plants, this carrier could play an important role in several metabolic processes including primary amino acid synthesis (ammonium assimilation), fatty acid metabolism (mobilization during seed germination), gluconeogenesis, and isoprenoid biosynthesis. It may also be involved in the export of mitochondrial redox equivalents to the cytosol via the so-called 'malate-oxaloacetate' shuttle [21].

In this study we provide evidence that the gene products of At2g22500, At4g24570 and At5g09470, named DIC1, DIC2 and DIC3, respectively, are isoforms of the dicarboxylate carrier in Arabidopsis. These proteins are 313, 313 and 337 amino acids long, respectively, possess the characteristic sequence features of the MCF (see $[2,4]$ and references therein) and 
display a high homology (55\%-70\% identical amino acids and 68\%-81\% similarity). DIC1, DIC2 and DIC3 were overexpressed in Escherichia coli, purified, reconstituted in phospholipid vesicles and identified from their transport properties and kinetic characteristics as DICs. This report presents the first identification of three isoforms of the dicarboxylate carrier and their genes in plants.

\section{EXPERIMENTAL}

\section{Plant Material and Growth Conditions}

Arabidopsis thaliana (ecotype Columbia) was grown in a greenhouse under either long-day (16h light/8h dark; at $\left.19.5^{\circ} \mathrm{C} / 17.5^{\circ} \mathrm{C}\right)$ or short-day $\left(8 \mathrm{~h}\right.$ light/ $16 \mathrm{~h}$ dark, at $\left.19.5^{\circ} \mathrm{C} / 17.5^{\circ} \mathrm{C}\right)$ conditions. Natural light was supplemented with white fluorescent light to provide $200 \mu \mathrm{mol}$ of photons $\mathrm{s}^{-1} \mathrm{~m}^{-2}$.

\section{Quantitative Real-Time PCR}

Total RNA, isolated from various tissues of A. thaliana using TRIzol (Life Technologies), was reverse transcribed with the GeneAmp RNA PCR Core kit (Applied Biosystems) with random hexamers as primers. The integrity of the starting RNA was verified by gel electrophoresis. Primers and probes based on the cDNA sequences of DIC1 and DIC3 were designed with Primer Express (Applied Biosystems). The forward and reverse primers corresponded to nucleotides 1032-1050 and 1083-1102 for DIC1, and to nucleotides 398-421 and 478-498 for DIC3. The carboxyfluorescein-Dark Quencher-labeled probes corresponded to nucleotides 1061-1076 and 431-450 of DIC1 and DIC3 cDNAs, respectively. For DIC2, the inventoried assay reagent (assay ID At02237780_s1) purchased from Applied Biosystems was used. Each $25-\mu \mathrm{L}$ PCR mixture contained $5 \mu \mathrm{L}$ of template $(0.2 \mu \mathrm{g}$ of reverse transcribed first-strand cDNA), 1x ABI universal master mixture (Applied Biosystems), $900 \mathrm{nM}$ each primer and $300 \mathrm{nM}$ probe for each gene. Negative controls without template were also performed. Thermal cycling was completed on a 7000 Sequence Detector System (Applied Biosystems) using the default program of $2 \mathrm{~min}$ at $50^{\circ} \mathrm{C}, 10 \mathrm{~min}$ at $95^{\circ} \mathrm{C}$ followed by 40 cycles of $15 \mathrm{~s}$ at $95^{\circ} \mathrm{C}$ and $1 \mathrm{~min}$ at $60^{\circ} \mathrm{C}$. The PCR products were analyzed using the Sequence Detection System software 1.0 (Applied Biosystems). Quantification of the absolute number of RNA copies was performed by interpolation in standard regression curves of $C_{\mathrm{T}}$ (cycle threshold) values generated using known concentrations of DIC1, DIC2 or DIC3 cDNA [22]. The cDNAs, purified and quantified spectrophotometrically, were used to make 
10-fold serial dilutions from $10^{2}$ to $10^{8}$ copies of plasmid DNA. The same PCR master mix and thermocycler parameters were used as described above. Our experimental conditions revealed 100 mRNA copies of DIC1, DIC2 or DIC3 with a detection rate of $100 \%$ ( 8 of 8 replicates). The detection rate, however, was about 30\% with 10 mRNA molecules.

\section{Bacterial Expression and Purification of DIC Proteins}

The coding sequences of DIC1 and DIC2 were amplified from the respective EST clones (AV538627 and AV541285) by PCR. The coding sequence of DIC3 was RT-PCR-amplified from flower bud RNA using $p f u$ polymerase. Forward and reverse primers corresponding to the extremities of the DIC coding sequences were synthesized with additional NdeI and EcoRI sites (shown in italics), respectively (DIC1 forward 5'GTCTTCATATGGGTCTAAAGGG-3', and reverse 5'-CTCTTGTGAATTCAAAAGTC-3'; DIC2 forward 5'-CCACACATATGGAGTCAAAAG-3', and reverse 5'GAATGAATTCAAAAATCTCG-3'; and DIC3 forward 5'CGTTCATATGGGCTTCAAACC-3', reverse 5'-TGAAGAATTCTGGGAATCTCAA-3'). The PCR products were sequenced and cloned into the pMW7 expression vector. The sequences of the inserts were verified using the BigDye ${ }^{\mathrm{TM}}$ Terminator kit (Perkin-Elmer) according to the manufacturer's instructions and an ABI Prism 3100 Genetic Analyzer (Applied Biosystems). The constructs were used to transform E. coli C0214(DE3) cells, and the recombinant DIC proteins were overproduced as inclusion bodies at $37^{\circ} \mathrm{C}$, as described previously [23]. Inclusion bodies were purified on a sucrose density gradient, washed at $4^{\circ} \mathrm{C}$ with TE buffer (10 mM Tris-HCl, $1 \mathrm{mM}$ EDTA, pH 7), then twice with a buffer containing Triton X-114 (3\%, w/v), $1 \mathrm{mM}$ EDTA and $10 \mathrm{mM}$ PIPES-NaOH, pH 7.0, and once again with TE buffer [23]. DIC proteins were solubilized in $1.7 \%(\mathrm{w} / \mathrm{v})$ sarkosyl, $0.1 \mathrm{mM}$ EDTA and $10 \mathrm{mM}$ Tris-HCl, $\mathrm{pH}$ 7.0. Small insoluble residues were removed by centrifugation at $258000 \mathrm{~g}$ for $1 \mathrm{~h}$ at $4^{\circ} \mathrm{C}$.

\section{Reconstitution into Liposomes and Transport Measurements}

The recombinant proteins in sarkosyl were reconstituted into liposomes in the presence of substrates, as described previously [24]. External substrate was removed from proteoliposomes on Sephadex G-75 columns (Pharmacia). Transport at $25^{\circ} \mathrm{C}$ was started by adding $\left[{ }^{35} \mathrm{~S}\right]$ sulphate, $\left[{ }^{14} \mathrm{C}\right]$ malate or $\left[{ }^{33} \mathrm{P}\right]$ phosphate (Amersham) to the proteoliposomes and terminated by addition of $30 \mathrm{mM}$ pyridoxal 5'-phosphate and $10 \mathrm{mM}$ bathophenanthroline 
(the "inhibitor-stop" method [24]). In controls, the inhibitors were added with the labeled substrate. The transport measurements were carried out at the same internal and external $\mathrm{pH}$ value of 7.0. External radioactivity was removed from quenched samples on Sephadex G-75 columns, and internal radioactivity was measured [24]. The experimental values were corrected by subtracting control values. The initial transport rate was calculated from the radioactivity taken up by proteoliposomes after $20 \mathrm{~s}$ (in the initial linear range of substrate uptake).

\section{Other Methods}

Proteins were separated by SDS-PAGE and stained with Coomassie Blue. The N-termini were sequenced and the amount of purified proteins was estimated by laser densitometry of stained samples using carbonic anhydrase as a protein standard [25]. The amount of protein incorporated into liposomes was measured, as described previously [25]; in all cases, it was about $25 \%$ of the protein added to the reconstitution mixture.

\section{RESULTS}

\section{Isolation and Characterization of DIC cDNAs}

The protein sequence of the human DIC, encoded by the SLC25A10 gene [2,26], was used to search databases for homologous plant sequences. Several related ESTs were identified that corresponded to the Arabidopsis thaliana genes At2g22500 and At4g24570. The cDNAs corresponding to the EST database entries AV538627 and AV541285 were retrieved from the Kazusa DNA Research Institute (Japan) and sequenced. Their complete nucleotide sequences corresponded to "full-length" cDNAs (including 5'UTR and 3'UTR sequences). One of these cDNAs contained a 942-bp ORF that encoded a polypeptide of 313 amino acids (heretofore named DIC1) with a calculated molecular mass of $33.4 \mathrm{kDa}$ (Figure 1). Analysis of the other cDNA revealed a 942-bp ORF encoding a 313 amino acid polypeptide (DIC2) with a calculated molecular mass of $32.9 \mathrm{kDa}$ (Figure 1). By screening Arabidopsis databases, we identified another gene (At5g09470) that was also related to the human DIC but had no reported ESTs. The absence of ESTs for At5g09470 raised the question of whether it was a pseudo-gene. However, PCR experiments using different cDNA libraries indicated that its RNA was present in flower buds and siliques (data not shown). Therefore, the coding region of this gene was RT-PCR-amplified from flower bud RNA using primers based on the genomic sequence of At5g09470. The deduced protein sequence of DIC3 consisted of 337 
amino acids with a molecular mass of $36.1 \mathrm{kDa}$ (Figure 1). DIC1 and DIC2 share $70 \%$ identical amino acids, whereas the protein sequence of DIC3 is $55 \%$ to $60 \%$ identical to those of the other two Arabidopsis DICs. The major difference between DIC3 and the other two DIC proteins is the presence of several small insertions in a segment of DIC3 located after the first 36 N-terminal residues (Figure 1). Therefore, DIC1 and DIC2 are more closely related, as is also indicated by the fact that their genes contain no introns, whereas the DIC3 gene possesses a canonical type II intron spanning the 428-686 nucleotide region of the At5g09470 sequence. All three Arabidopsis DIC proteins belong to the MCF given their tripartite structure, the presence of two hydrophobic regions in each repeat and the three-fold repetition of the signature motif (Figure 1).

\section{Molecular and Phylogenetic Relationship of Arabidopsis DIC Proteins with Other}

\section{Mitochondrial Transporters}

Amino acid sequence comparisons revealed that Arabidopsis DICs showed the highest degree of similarity with other plant proteins that had been annotated as putative (oxo)dicarboxylate carriers in databases. For example, DIC1 exhibited $73 \%$ identity with a putative DIC from Trifolium pratense (BAE71294), 68\% identity with a putative carrier protein from Oryza sativa (EAZ07364), 67\% identity with a putative uncoupling protein from Saccharum officinarum (AAU11466), and 60\% identity with a 2-oxoglutarate carrier-like protein from $O$. sativa (BAD17507). Among mitochondrial transporters from other organisms, Arabidopsis DICs showed the highest homology with the already identified mitochondrial DICs, sharing $42 \%$ identical amino acids with the human DIC [26] and 37\% with the Caenorhabditis elegans DIC [27]. Furthermore, the MCF member in Saccharomyces cerevisiae most closely related to the Arabidopsis DICs was the yeast DIC [6], though with only $32 \%$ identity. A phylogenetic analysis (Figure 2) carried out using the Arabidopsis DIC sequences and other mitochondrial carriers for di- and tri-carboxylates as well as those of uncoupling proteins revealed that DIC1, DIC2 and DIC3 are monophyletic and form a group close to those of nonplant DICs, the plant dicarboxylate-tricarboxylate carriers (DTCs) and animal oxoglutarate carriers. However, plant and animal DICs formed two distinct clusters with the yeast DIC belonging to the latter. In addition, the high degree of homology between DIC1, DIC2 and DIC3 strongly suggested that they may be isoforms of the same transporter. 


\section{Expression of DICs in Plant Organs}

The TAIR database indicates that DIC1 (108 ESTs) and DIC2 (70 ESTs) are more highly expressed than DIC3 (0 ESTs). The expression of the DIC isoforms in A. thaliana was examined in different tissues by quantitative real-time PCR. To determine the absolute number of RNA copies of DIC1, DIC2 and DIC3, standard calibration curves were constructed using $10^{2}$ to $10^{8}$ copies of their cDNAs. Under our experimental conditions the threshold of 100 copies of each gene was detected with accuracy and reproducibility. From the fluorescence signals obtained with the different tissue samples interpolated in the calibration curves, the number of RNA copies was calculated to vary between 67583 and 281397 per $\mu$ g total RNA for DIC1 and between 71176 and 224582 per $\mu$ g total RNA for DIC2 (Figure 3). DIC1 was more expressed in root and stem than in flowers, leaf and seedling, whereas DIC2 more in stem, root and leaf than in seedling and flowers. The number of mRNA copies of DIC3 in the investigated tissues was below the detection limit of 500 copies per $\mu \mathrm{g}$ total RNA. These observations are in good agreement with the Arabidopsis gene expression data in public microarray data collections (available at Genevestigator: https://www.genevestigator.ethz.ch/) [28] which show that DIC1 and DIC2 are expressed in all the tissues at comparable levels and that the expression of DIC3 is very low or absent.

\section{Bacterial Expression and Functional Characterization of Recombinant DIC Proteins}

DIC1, DIC2 and DIC3 were expressed at high levels in E. coli C0214(DE3). They accumulated as inclusion bodies and were purified by centrifugation and washing (Figure 4, lanes 3, 6 and 9). The identity of the purified proteins was confirmed by N-terminal sequencing. Approximately 70-100 mg of each purified protein per liter of culture was obtained. The proteins were not detected in cells harvested after induction of expression but lacking the coding sequence in the vector (Figure 4, lanes 1, 4 and 7) nor in bacteria harvested immediately before induction (data not shown).

Each recombinant protein was reconstituted into liposomes and their transport activities for potential substrates were tested in homo-exchange experiments (i.e., with the same substrate inside and outside). In the reconstituted system, DIC1, DIC2 or DIC3 catalyzed an active $[35$ S $]$ sulphate/sulphate exchange that was completely inhibited by a mixture of pyridoxal 5'-phosphate and bathophenanthroline. They did not catalyze homo-exchanges for pyruvate, citrate, carnitine, glutamate and ATP (internal concentration, $10 \mathrm{mM}$; external concentration, $1 \mathrm{mM}$ ) (data not shown). Importantly, no $\left[{ }^{35} \mathrm{~S}\right]$ sulphate/sulphate exchange 
activity was detected if the protein had been boiled before incorporation into liposomes or if proteoliposomes were reconstituted with sarkosyl-solubilized material from bacterial cells either lacking the expression vector for DIC or harvested immediately before induction of expression. Likewise, no such activity was detected in liposomes reconstituted with three unrelated mitochondrial carriers, Ort1p [29], Ggc1p [30] and Sam5p [31], which had been expressed and purified from E. coli CO214(DE3).

As shown in Figure 5, the uptake of $\left[{ }^{35} \mathrm{~S}\right]$ sulphate by sulphate/sulphate exchange, catalyzed by DIC2, followed a first-order kinetics (rate constant, $0.41 \mathrm{~min}^{-1}$; initial rate, 327 $\mu \mathrm{mol} / \mathrm{min}$ per g protein) with isotopic equilibrium being reached exponentially. In contrast, no $\left[{ }^{35}\right.$ S] sulphate uptake was observed without internal substrate (Figure 5), demonstrating that DIC2 does not catalyze unidirectional transport (uniport) but only an exchange of substrates. Similar results were obtained with reconstituted DIC1 and DIC3.

The substrate specificity of the three reconstituted $A$. thaliana DIC proteins was investigated in detail by measuring the uptake of $\left[{ }^{35} \mathrm{~S}\right]$ sulphate into proteoliposomes that had been pre-loaded with a variety of potential substrates. DIC1 and DIC2 allowed ${ }^{35}$ S]sulphate to be exchanged with internal sulphate, phosphate, arsenate, thiosulphate, malate, malonate, succinate, oxaloacetate, maleate or oxalate (Figure 6). DIC3 yielded higher activities of $\left[{ }^{35}\right.$ S $]$ sulphate uptake with internal sulphate, thiosulphate, oxaloacetate and oxalate than with phosphate, arsenate, malate, malonate, succinate and maleate (Figure 6). Each of the three DICs exhibited very low transport activity with internal sulphite and 2-oxoglutarate, whereas virtually no transport was detected with internal fumarate, aspartate, citrate, cis-aconitate, (Figure 6) and (not shown) arginine, ATP, carnitine, pyruvate, glutamate, glutamine or glutathione. Notably, in liposomes reconstituted with DIC1 and DIC2 [ ${ }^{35}$ S]sulphate exchanged better with sulphate than with thiosulphate and with malonate rather than with oxalate, whereas in liposomes reconstituted with DIC3 [ ${ }^{35}$ S $]$ sulphate exchanged better with oxalate than with malonate.

The $\left[{ }^{35} \mathrm{~S}\right]$ sulphate/sulphate exchange reaction catalyzed by the three Arabidopsis DIC proteins was inhibited strongly by pyridoxal 5'-phosphate, bathophenanthroline, bromocresol purple and mercuric chloride (Figure 7). The organic mercurials, mersalyl and p-hydroxymercuribenzoate, and the impermeable dicarboxylate analogues, butylmalonate and phenylsuccinate, markedly inhibited the activity of DIC1 and DIC2 and to a lesser extent that of DIC3. In contrast, inhibitors of other characterized mitochondrial carriers, such as 
N-ethylmaleimide, $\alpha$-cyano-4-hydroxycinnamate, carboxyatractyloside and bongkrekic acid and (not shown) 1,2,3-benzenetricarboxylate had very little effect on the activity of the Arabidopsis DIC proteins.

\section{Kinetic Characteristics of the Recombinant DIC Proteins}

The kinetic constants of the recombinant purified Arabidopsis DIC proteins were determined by measuring the initial transport rate at various external $\left[{ }^{35} \mathrm{~S}\right]$ sulphate, $\left[{ }^{14} \mathrm{C}\right]$ malate or $\left[{ }^{33} \mathrm{P}\right]$ phosphate concentrations in the presence of a constant saturating internal concentration of the same substrate (homo-exchange). The mean $\mathrm{Km}$ and Vmax values and their standard errors are shown in Table I. For each DIC protein, the specific activity (Vmax) was not significantly different for the three substrates tested. Howeyer, DIC3 displayed a Vmax value that was approximately one order of magnitude higher than that of DIC1 and 2-fold higher than that of DIC2. The apparent transport affinity $(\mathrm{Km})$ of all three DIC proteins for sulphate was lower than the Km values for phosphate and malate, which were very similar to each other. In the case of DIC3, the Km for sulphate was one order of magnitude lower than the $\mathrm{Km}$ values for phosphate and malate. In addition, the Km of DIC3 for sulphate was 3-4-fold lower than the Km values of DIC1 and DIC2 for the same substrate.

\section{DISCUSSION}

In plants, as in animals, knowledge concerning the mitochondrial dicarboxylate carrier has existed for a long time, and its main properties have been studied in isolated intact mitochondria (for a review see $[1,3]$ and references therein). However, in plants the protein(s) responsible for the dicarboxylate carrier had not been hitherto identified. The results reported in this study demonstrate that we have identified DIC1, DIC2 and DIC3 as isoforms of the dicarboxylate carrier in $A$. thaliana, because the properties of the recombinant and reconstituted proteins closely resemble those of the native plant and animal DICs in substrate specificity, transport affinities and inhibitor sensitivity.

Similar to the biochemically characterized DICs from non-plant organisms, DIC1, DIC2 and DIC3 transport malate, oxaloacetate, succinate, maleate, malonate, phosphate, sulfate and thiosulfate. The substrate specificity of the Arabidopsis DIC proteins is distinct from any other mitochondrial carrier of known function, including the related oxoglutarate [32], succinate/fumarate [33], oxaloacetate [34] and oxodicarboxylate [35] carriers (whose 
principal substrates are 2-oxoglutarate and malate, succinate and fumarate, oxaloacetate and sulfate, oxoadipate and oxoglutarate, respectively). It also partially differs from that of mammalian and yeast DICs, which are their closest sequence homologs. Thus, Arabidopsis DICs transport oxaloacetate, sulfate and thiosulfate more efficiently than animal DICs as well as oxoglutarate, though to a very low extent. Furthermore, compared to rat, C. elegans and yeast DICs, the plant carriers show similar Km values for malate $(0.4-0.79 \mathrm{mM})$ but lower $\mathrm{Km}$ values for phosphate (0.47-0.69 $\mathrm{mM}$ vs $1.41-1.77 \mathrm{mM})$. These differences are probably accounted for by the phylogenic analysis reported in Figure 2, since Arabidopsis DICs form a separate clade with respect to fungal and animal DICs. Plants, yeast and mammals appear to have evolved different types of mitochondrial carriers for di-and tri-carboxylic acids: the dicarboxylate, oxoglutarate, oxoadipate/oxoglutarate and citrate carriers in mammals; the dicarboxylate, oxaloacetate, succinate/fumarate, oxoadipate/oxoglutarate and citrate carriers in yeast; and the dicarboxylate, succinate/fumarate and dicarboxylate-tricarboxylate carriers in plants. Interestingly, plants appear to contain "hybrid" carriers when compared to yeast and mammals: their DTC possesses the combined characteristics of the mammalian oxoglutarate and citrate carriers [12] and DIC exhibits the combined characteristics of the yeast dicarboxylate and oxaloacetate carriers (this work).

Although the Arabidopsis DIC isoforms have many properties in common, they differ in some respects. Relative to sulfate transport, dicarboxylates, phosphate and arsenate are transported more efficiently by DIC1 and DIC2 than by DIC3, whereas thiosulfate and oxaloacetate are more efficiently transported by DIC3 when compared to DIC1 and DIC2. Furthermore, DIC3 is inhibited considerably less by butylmalonate and phenylsuccinate, as well as by the organic mercurials, with respect to DIC1 and DIC2. These differences are consistent with the fact that DIC1 and DIC2 share 70\% identical amino acids, whereas DIC3 shares only $55 \%$ to $60 \%$ identical amino acids with DIC1 and DIC2. Indeed, DIC3 seems to exhibit a substrate specificity that resembles more the yeast OAC.

In a series of studies, DIC1, DIC2 and DIC3 have been reported to be mitochondrial uncoupling proteins named AtPUMP4-6 [36-38]. This conclusion was based on sequence homologies between AtPUMP1-3 and DIC1, DIC2 and DIC3 [36-38] and on the observation that recombinant AtPUMP6 (i.e., DIC3) mediated a linoleic acid-stimulated $\mathrm{H}^{+}$flux in reconstituted liposomes [37]. However, DIC1, DIC2 and DIC3 are phylogenetically closer to animal and yeast DICs than to uncoupling proteins including AtPUMP1-3 (Figure 2); recombinant and purified DIC1, DIC2 and DIC3 all transport the characteristic substrates of the dicarboxylate carrier by an exchange mechanism (this study). Linoleic acid may increase 
the permeability of the proteoliposomes in a non-DIC3-specific manner; the Vmax of the reported $\mathrm{H}^{+}$flux [37] is approximately an order of magnitude lower than the Vmax of dicarboxylate transport by DIC3 (this work). Furthermore, even if solid evidence for a DIC3mediated $\mathrm{H}^{+}$flux were provided, this finding alone would not be enough to identify DIC3 as an uncoupling protein instead of a DIC, as our phylogenetic analysis (Figure 2) suggests and direct metabolite transport assays (Figure 6) demonstrate. In fact, it has been reported that the dicarboxylate carrier is involved in the protonophoric action of fatty acids in mitochondria [39]. Moreover, a carrier-dependent fatty acid-stimulated flux of $\mathrm{H}^{+}$has often been observed in mitochondria and liposomes reconstituted with mitochondrial carriers [40-42].

Expression analyses of the Arabidopsis DIC genes show that DIC1 and DIC2 are present in all of the plant tissues/organs analyzed, implying that DIC plays an essential role in plant cell metabolism. However, a functional redundancy may exist between the DIC isoforms as well as between the dicarboxylate carrier and other similar plant MCF members such as the DTC and succinate/fumarate carrier (SFC). Our results further show that DIC1 and DIC2 exhibit comparable levels of expression. In addition, under certain stress conditions subtle differences emerge in DIC isoform expression. DIC1 expression is reduced under anoxia and hypoxia, whereas DIC2 expression is reduced by UV treatment. Conversely, DIC1 expression is increased by salt stress and DIC2 by treatment with hydrogen peroxide (data not shown). Such differences could suggest that these DIC isoforms might have specific functions, perhaps in specific plant tissues/organs.

Because the DICs transport a broad spectrum of dicarboxylates, they may potentially play a role in a number of important metabolic functions that require organic acid flux to or from the mitochondria. Firstly, it is very likely that DIC plays an anaplerotic role, leading to the transport of dicarboxylic acids into the mitochondria (in exchange for phosphate or sulfate), which are then used as respiratory substrates. This function is further supported by the early findings that malate and succinate oxidation by plant mitochondria is inhibited by dicarboxylate carrier inhibitors $[43,44]$. Secondly, the malate/oxaloacetate exchange catalyzed by DIC, coupled with the cytosolic and mitochondrial NAD-dependent malate dehydrogenase activities, would allow the transfer of reducing equivalents (i.e., NADH) from the mitochondrial matrix to the cytosol (and vice versa). Redox shuttles are important in photosynthetic organs such as the leaves of C3 plants. The chloroplastic malate valve (see [45]) and mitochondrial malate/oxaloacetate shuttle are involved in the light-dependent photorespiratory cycle that requires malate to be shifted to the peroxisomes for the production of NADH in the synthesis of glycerate from hydroxypyruvate [46,47]. Indeed, it was shown 
that mitochondria can produce $25 \%$ of the required reducing power for photorespiration via the malate/oxaloacetate shuttle ([46]. It had been reported that the mitochondrial redox shuttle was composed of two electrogenic uniporters linked for the sake of charge compensation [48]. However, this interpretation arose from artificial results due to high metabolite concentrations; a single malate/oxaloacetate antiporter is believed to carry out this function [21]. The DIC proteins described in this work possess the characteristics of the proposed malate shuttle. It was suggested that under normal cytosolic NADH/NAD levels, this carrier would only export reducing equivalents from the mitochondria [46]. Recently, it has been shown that the shuttle can be reversed and that the malate/oxaloacetate exchange across the inner mitochondrial membrane is the rate-limiting step in the import of redox equivalents to wheat and potato mitochondria [49]. The authors proposed the existence of a novel malate/oxaloacetate antiporter but could not prove it at the molecular level. When this mitochondrial carrier is coupled with the chloroplastic malate valve, the plant acquires the ability to balance the cellular energy supply and control redox poise [45]. Furthemore, shifting malate allows the production of NADH in the cytosol to fuel nitrate reductase, an important NADH-consuming enzyme that reduces nitrate to nitrite. In addition, the high expression of DIC1 and DIC2 in the cotyledons, as deduced from the public microarray data, and their capacity to transport succinate and malate suggest that they can play a role in the mobilization of storage lipids during germination and/or in gluconeogenesis.

The molecular identification of plant DICs paves the way to the evaluation of their individual role(s) within the mitochondrial membrane under different physiological conditions. This will require the isolation and characterization of mutants for each DIC isoform and perhaps the study of double or even triple mutants.

\section{ACKNOWLEDGMENTS}

N.P. was supported by a PhD grant from the French Ministry of National Education, Research and Technology and M.H. was funded by the Centre National de la Recherche Scientifique (CNRS) and the Uniyersité Paris Sud-XI. Research in the laboratories of F.P and L.P. was supported by grants from Ministero dell'Università e della Ricerca (MUR-PRIN and FIRB), Consiglio Nazionale delle Ricerche (CNR) and Centro di Eccellenza Geni in campo Biosanitaro ed Agroalimentare (CEGBA). We wish to thank the Kazusa DNA Reasearch Institute (Japan) for sending us EST clones. 


\section{REFERENCES}

1 Laloi, M. (1999) Plant mitochondrial carriers: an overview. Cell Mol. Life Sci. 56, 918-944

2 Palmieri, F. (2004) The mitochondrial transporter family (SLC25): physiological and pathological implications. Eur. J. Physiol-Pflugers Arch. 447, 689-709

3 Palmieri, F., Picault, N., Palmieri, L. and Hodges, M. (2004) Plant mitochondrial carriers. In Plant Mitochondria: From Genome to Function (Day, D.A., Millar, A.H. and Whelan, J., eds.), pp. 247-276, Kluwer Academic Press

4 Picault, N., Hodges, M., Palmieri, L. and Palmieri, F. (2004) The growing family of mitochondrial carriers in Arabidopsis. Trends Plant Sci. 9, 138-146

5 Palmieri, F., Agrimi, G., Blanco, E., Castegna, A., Di Noia, M.A., Iacobazzi, V., Lasorsa, F.M., Marobbio, C.M., Palmieri, L., Scarcia, P., Todisco, S., Vozza, A. and Walker, J. (2006) Identification of mitochondrial carriers in Saccharomyces cerevisiae by transport assay of reconstituted recombinant proteins. Biochim. Biophys. Acta 1757, 1249-62

6 Palmieri, L., Palmieri, F., Runswick, M.J. and Walker, J.E. (1996) Identification by bacterial expression and functional reconstitution of the yeast genomic sequence encoding the mitochondrial dicarboxylate carrier protein. FEBS Lett. 399, 299-302

7 Nelson, D.R., Felix, C.M. and Swanson, J.M. (1998) Highly conserved charge-pair networks in the mitochondrial carrier family. J. Mol. Biol. 277, 285-308

8 Baker, A. and Leaver, C.J. (1985) Isolation and sequence analysis of a cDNA encoding the ATP/ADP translocator of Zea mays L. Nucl. Acid Res. 13, 5857-5867

9 Laloi, M., Klein, M., Riesmeier, J., Muller-Rober, B., Fleury., Bouillaud, F. and Ricquier, D. (1997) A plant cold-induced uncoupling protein. Nature 389, 135-136 
10 Kiiskinen, M., Korhonen, M. and Kangasjärvi, J. (1997) Isolation and characterization of cDNA for a plant mitochondrial phosphate translocator (Mpt1): ozone stress induces Mpt1 mRNA accumulation in birch (Betula pendula Roth). Plant Mol. Biol. 35, 271-279

11 Takabatake, R., Hata, S., Taniguchi, M., Kouchi, H., Sugiyama, T. and Izui, K. (1999) Isolation and characterisation of cDNAs encoding mitochondrial phosphate transporters in soybean, maize, rice and Arabidopsis. Plant Mol. Biol. 40, 479-486

12 Picault, N., Palmieri, L., Pisano, I., Hodges, M. and Palmieri, F. (2002) Identification of a novel transporter for dicarboxylates and tricarboxylates in plant mitochondria. Bacterial expression, reconstitution, functional characterization, and tissue distribution. J. Biol. Chem. 277, 24204-24211

13 Hoyos, M.E., Palmieri, L., Wertin, T., Arrigoni, R., Polacco, J.C. and Palmieri, F. (2003) Identification of a mitochondrial transporter for basic amino acids in Arabidopsis thaliana by functional reconstitution into liposomes and complementation in yeast. Plant J. 33, 1027 1035

14 Palmieri, L., Arrigoni, R., Blanco, E., Carrari, F., Zanor, M.I., Studart-Guimaraes, C., Fernie, A.R. and Palmieri, F. (2006) Molecular identification of an Arabidopsis Sadenosylmethionine transporter. Analysis of organ distribution, bacterial expression, reconstitution into liposomes, and fünctional characterization. Plant Physiol. 142, 855-65

15 Bouvier, F., Linka, N., Isner, J-C., Mutterer, J., Weber, A.P.M. and Camara, B. (2006) Arabidopsis SAMT1 defines a plastid transporter regulating plastid biogenesis and plant development. Plant Cell 18, 3088-3105

16 Catoni, E., Desimone, M., Hilpert, M., Wipf, D., Kunze, R., Schneider, A., Flügge, U-I., Schumacher, K. and Frommer W.B. (2003a) Expression pattern of a nuclear encoded mitochondrial arginine-ornithine translocator gene from Arabidopsis. BMC Plant Biol. 3, 110 
17 Catoni, E., Schwab, R., Hilpert, M., Desimone, M., Schwacke, R., Flugge, U-I., Schumacher, K. and Frommer, W.B. (2003) Identification of an Arabidopsis mitochondrial succinatefumarate translocator. FEBS Lett. 534, 87-92

18 De Santis, A., Arrigoni, O. and Palmieri, F. (1976) Carrier-mediated transport of metabolites in purified bean mitochondria. Plant Cell Physiol. 17, 1221-1233

19 Krämer, R. and Palmieri, F. (1992) Metabolite carriers in mitochondria. In Molecular Mechanisms in Bioenergetics (Ernster, L. ed.), pp. 359-384, Elsevier Science Publishers B.V., Amsterdam

20 Palmieri, L., Vozza, A., Hönlinger, A., Dietmeier, K., Palmisano, A., Zara, V. and Palmieri, F. (1999) The mitochondrial dicarboxylate carrier is essential for the growth of Saccharomyces cerevisiae on ethanol or acetate as the sole carbon source.

Mol. Microbiol. 31, 569-577

21 Hanning, I., Baumgarten, K., Schott, K. and Heldt, H.W. (1999) Oxaloacetate transport into plant mitochondria. Plant Physiol. 119, 1025-1031

22 Sellars, M.J., Vuocolo, T., Leeton, L.A., Coman, G.J., Degnan, B.M. and Preston, N.P. (2007) Real-time RT-PCR quantification of Kuruma shrimp transcripts: a comparison of relative and absolute quantification procedures. J. Biotechnol. 129, 391-399

23 Palmieri, L., Pardo, B., Lasorsa, F.M., del Arco, A., Kobayashi, K., Iijima, M., Runswick, M.J., Walker, J.E., Saheki, T., Satrustegui, J. and Palmieri, F. (2001) Citrin and aralar1 are $\mathrm{Ca}(2+)$-stimulated aspartate/glutamate transporters in mitochondria. EMBO J. 20, 5060-9

24 Palmieri, F., Indiveri, C., Bisaccia, F. and Iacobazzi, V. (1995) Mitochondrial metabolite carrier proteins: purification, reconstitution, and transport studies. Methods Enzymol. 260, 349-369

25 Fiermonte, G., Dolce, V. and Palmieri, F. (1998) Expression in Escherichia coli, functional characterization, and tissue distribution of isoforms $\mathrm{A}$ and $\mathrm{B}$ of the phosphate carrier from bovine mitochondria. J. Biol. Chem. 273, 22782-22787 
26 Fiermonte, G., Dolce, V., Arrigoni, R., Runswick, M.J., Walker, J.E. and Palmieri, F. (1999) Organization and sequence of the gene for the human mitochondrial dicarboxylate carrier: evolution of the carrier family. Biochem. J. 344, 953-960

27 Fiermonte, G., Palmieri, L., Dolce, V., Lasorsa, F.M., Palmieri, F., Runswick, M.J. and Walker, J.E. (1998) The sequence, bacterial expression, and functional reconstitution of the rat mitochondrial dicarboxylate transporter cloned via distant homologs in yeast and Caenorhabditis elegans. J. Biol. Chem. 273, 24754-24759

28 Zimmermann, P., Hirsch-Hoffmann, M., Hennig, L. and Gruissem, W. (2004) GENEVESTIGATOR. Arabidopsis microarray database and analysis toolbox. Plant Physiol. 136, 2621-2632

29 Palmieri, L., De Marco, V., Iacobazzi, V., Palmieri, F,, Runswick, M.J. and Walker, J.E. (1997) Identification of the yeast ARG-11 gene as a mitochondrial ornithine carrier involved in arginine biosynthesis. FEBS Lett. 410, 447-451

30 Vozza, A., Blanco, E., Palmieri, L. and Palmieri, F. (2004) Identification of the mitochondrial GTP/GDP transporter in Saccharomyces cerevisiae. J. Biol. Chem. 279, 20850-20857

31 Marobbio, C.M.T., Agrimi, G., Lasorsa, F.M. and Palmieri, F. (2003) Identification and functional reconstitution of yeast mitochondrial carrier for S-adenosylmethionine. EMBO J.

32 Runswick, M.J., Walker, J.E., Bisaccia, F., Iacobazzi, V. and Palmieri, F. (1990) Sequence of the bovine 2-oxoglutarate/malate carrier protein: structural relationship to other mitochondrial transport proteins. Biochemistry 29, 11033-40

33 Palmieri, L., Lasorsa, F.M., De Palma, A., Palmieri, F., Runswick, M.J. and Walker, J.E. (1997) Identification of the yeast ACR1 gene product as a succinate-fumarate transporter essential for growth on ethanol or acetate. FEBS Lett. 417, 114-118 
34 Palmieri, L., Vozza, A., Agrimi, G., De Marco, V., Runswick, M.J., Palmieri, F. and Walker, J.E. (1999) Identification of the yeast mitochondrial transporter for oxaloacetate and sulfate. J. Biol. Chem. 274, 22184-90

35 Fiermonte, G., Dolce, V., Palmieri, L., Ventura, M., Runswick, M.J., Palmieri, F. and Walker, J.E. (2001) Identification of the human mitochondrial oxodicarboxylate carrier: bacterial expression, reconstitution, functional characterization, tissue distribution, and chromosomal location. J. Biol. Chem. 276, 8225-8230

36 Nogueira, F.T.S., Borecky, J., Vercesi, A.E. and Arruda, P. (2005) Genomic structure and regulation of mitochondrial uncoupling protein genes in mammals and plants. Biosci. Rep. 25, 209-226

37 Borecky, J., Nogueira, F.T.S., de Oliveira, K.A.P., Maia, I.G., Vercesi, A.E. and Arruda, P. (2006) The plant energy-dissipating mitochondrial systems: depicting the genomic structure and the expression profiles of the gene families of uncoupling protein and alternative oxidase in monocots and dicots. J. Exp. Bot. 57, 849-864

38 Vercesi, A.E., Borecky, J., Maia, I.G., Arruda, P., Cuccovia, I.M. and Chaimovich, H. (2006) Plant uncoupling mitochondrial proteins. Annu. Rev. Plant Biol. 57, 383-404

39 Wieckowski, M.R. and Wojtczak, L. (1997) Involvement of the dicarboxylate carrier in the protonophoric action of long-chain fatty acids in mitochondria. Biochem. Biophys. Res. Commun. 232, 414-417

40 Brustovetsky, N. and Klingenberg, M. (1994) The reconstituted ADP/ATP carrier can mediate $\mathrm{H}^{+}$transport by free fatty acids, which is further stimulated by mersalyl. J. Biol. Chem. 269, 27329-27336

41 Samartsev, V.N., Mokhova, E.N. and Skulachev, V.P. (1997) The pH-dependent reciprocal changes in contributions of $\mathrm{ADP} / \mathrm{ATP}$ antiporter and aspartate/glutamate antiporter to the fatty acid-induced uncoupling. FEBS Lett. 412, 179-182 
42 Samartsev, V.N., Smirnov, A.V., Zeldi, I.P., Markova, O.V., Mokhova, E.N. and Skulachev, V.P. (1997) Involvement of aspartate/glutamate antiport in fatty acid-induced uncoupling of liver mitochondria. Biochim. Biophys. Acta 1319, 251-257

43 Wiskich, J.T. (1975) Phosphate dependent substrate transport into mitochondria. Oxidative studies. Plant Physiol. 56, 121-125.

44 Day, D.A. and Hanson, J.B. (1997) Effect of phosphate and uncouplers on substrate transport and oxidation by isolated corn mitochondria. Plant Physiol. 59, 139-144.

45 Scheibe, R. (2004) Malate valves to balance cellular energy supply, Physiol. Plant. 120, 2126

46 Hanning, I. and Heldt, H.W. (1993) On the function of mitochondrial metabolism during photosynthesis in spinach (Spinacia oleracea L.) leaves. Partitioning between respiration and export of redox equivalents and precursors for nitrate assimilation products. Plant Physiol. 103, $1147-1154$

47 Raghavendra, A.S., Reumann, S. and Heldt, H.W. (1998) Participation of mitochondrial metabolism in photorespiration. Reconstituted system of peroxisomes and mitochondria from spinach leaves. Plant Physiol. 116, 1333-1337

48 Zoglowek, C., Krömer, S. and Heldt, H.W. (1988) Oxaloacetate and malate transport by plant mitochondria. Plant Physiol. 87, 109-115

49 Pastore, D., Di Pede, S. and Passarella, S. (2003) Isolated durum wheat and potato cell mitochondria oxidize externally added NADH mostly via the malate/oxaloacetate shuttle with a rate that depends on the carrier-mediated transport. Plant Physiol. 133, 2029-2039 
Table I Kinetic constants of substrate uptake into proteoliposomes reconstituted with recombinant DIC1, DIC2 or DIC3

Data were obtained from Lineweaver-Burk plots of the rates of the homo-exchanges (the same substrate inside and outside) under variation of the external substrate concentration. The concentration of the internal substrate was $20 \mathrm{mM}$. The values given in the table are the means \pm S.E. of at least four independent experiments.

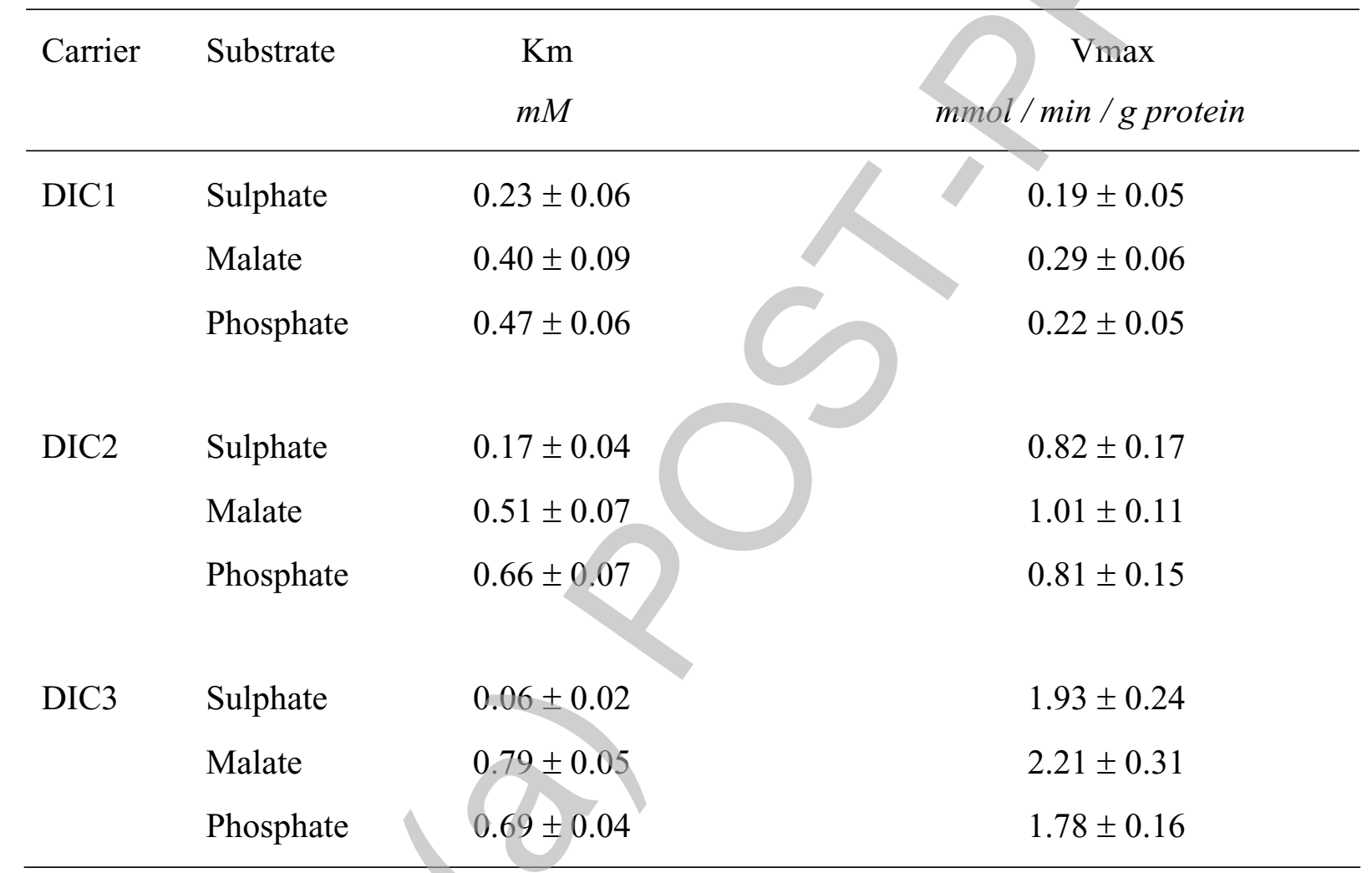




\section{FIGURE LEGENDS}

Figure 1 Sequence alignment of the three Arabidopsis DIC proteins. The deduced amino acid sequences of the DIC genes were aligned using CLUSTAL X with identical residues indicated by black boxes. Added gaps are given by hyphens. Solid lines were placed below the conserved motif that is characteristic of the mitochondrial carrier protein family.

Figure 2 Phylogenic tree of amino acid sequences of mitochondrial transporters from various organisms. The unrooted dendogram originated from an alignment performed by CLUSTAL X (1.75) software using default parameters and visualized using Phylodendron TreePrint (http://www.es.embnet.org/Doc/phylodendron/treeprint-form.html). Branch lengths are drawn proportional to the amount of sequence change. The bar indicates the number of substitutions per residue with 0.1 corresponding to a distance of 10 substitutions per 100 residues. The proteins have the following accession numbers: yeast-DIC, U79459; C. elegansDIC, X76114; human-DIC, AJ131613; mouse-DIC, AF188712; rat-DIC, AJ223355; milletDTC, D45073; At-DTC, AJ311780; tobacco-DTC, Q8SF04; C. elegans-OGC, AAB37890; bovine-OGC, M60662; rat-OGC, U84727; human-OGC, X66114; human-UCP5, O95258; At-PUMP3, F7A19_22; human-UCP4, 095847; At-PUMP1, CAA11757; At-PUMP2, NP_568894; rat-UCP1, P04633; human-UCP1, P25874; human-UCP2, P55851; rat-UCP2, P56500; rat-UCP3, P56499; human-UCP3, P55916; yeast-OAC, P32332; At4g03115, NP_680566; At-SFC, 15450697; yeast-SFC, Z49595; yeast-CIC, U17503; C. elegans-CIC, P34519; bovine-CIC, P79110; rat-CIC, P32089; human-CIC, BC004980; At-DIC3, AM236861; At-DIC1, AM236862; and At-DIC2, AM236863. Abbreviations: DIC, dicarboxylate carrier; DTC, di- and tricarboxylate carrier; OGC, oxoglutarate carrier; PUMP and UCP, uncoupling proteins; OAC, oxaloacetate carrier; SFC, succinate/fumarate carrier; CIC, citrate carrier.

Figure 3. Expression of Arabidopsis DIC in various tissues. Quantitative real-time PCR experiments of DiC1 (gray bars) and DIC2 (black bars) were conducted on cDNAs prepared by reverse transcription of total RNAs from the indicated tissues using specific primers and probes based on Arabidopsis DIC. The values in number of copies / $\mu \mathrm{g}$ total RNA are the means \pm S.E. of four independent experiments. 
Figure 4 Expression in Escherichia coli and purification of Arabidopsis DIC proteins. Proteins were separated by $12.5 \%$ SDS-PAGE and stained with Coomassie Blue dye. Indicated molecular mass sizes on the left-hand side column correspond to bovine serum albumin, ovotransferrin, carbonic anhydrase and cytochrome c; Lanes 1 and 2, E. coli C0214(DE3) containing the expression vector with (lane 2) and without (lane 1) the DIC1 coding sequence; lanes 4 and 5, E. coli C0214(DE3) containing the expression vector with (lane 5) and without (lane 4) the DIC2 coding sequence; lanes 7 and 8, E. coli C0214(DE3) containing the expression vector with (lane 8) and without (lane 7) the DIC3 coding sequence; lanes 3, 6 and 9, purified DIC1, DIC2 and DIC3 originating from bacteria shown in lanes 2, 5 and 8 , respectively. Samples were taken $5 \mathrm{~h}$ after induction. The same number of bacteria was analyzed in each sample.

Figure 5 Kinetics of $\left[{ }^{35} \mathrm{~S}\right]$ sulphate transport in proteoliposomes reconstituted with DIC2. $0.1 \mathrm{mM}\left[{ }^{35} \mathrm{~S}\right]$ sulphate was added to proteoliposomes containing $10 \mathrm{mM}$ sulphate (exchange, -) or $5 \mathrm{mM} \mathrm{NaCl}$ and no substrate (uniport, $\mathrm{O}$ ). Similar results were obtained in three independent experiments.

Figure 6 Substrate specificity of DIC1, DIC2 and DIC3. Liposomes, reconstituted with DIC1 in A, DIC2 in B and DIC3 in C, were preloaded internally with various substrates (concentration $20 \mathrm{mM}$ ). Transport was started by the addition of $0.1 \mathrm{mM}\left[{ }^{35} \mathrm{~S}\right]$ sulphate and terminated after $20 \mathrm{~s}$. The values are the means \pm S.E. of at least three independent experiments.

Figure 7 Effect of inhibitors on the $\left[{ }^{35} \mathrm{~S}\right]$ sulphate/sulphate exchange by DIC1, DIC2 and DIC3. Proteoliposomes were pre-loaded internally with $20 \mathrm{mM}$ sulphate and transport was initiated by adding $0.1 \mathrm{mM}\left[{ }^{35} \mathrm{~S}\right]$ sulphate to proteoliposomes reconstituted with DIC1 (white bars), DIC2 (gray bars), or DIC3 (black bars). The incubation time was $20 \mathrm{~s}$. Thiol reagents and $\alpha$-cyano-4-hydroxycinnamate were added $2 \mathrm{~min}$ before the labeled substrate; the other inhibitors were added together with $\left[{ }^{35} \mathrm{~S}\right]$ sulphate. The final concentrations of the inhibitors were $0.1 \mathrm{mM}$ for mersalyl (MER), p-hydroxymercuribenzoate (HMB) and mercuric chloride $\left(\mathrm{HgCl}_{2}\right) ; 2 \mathrm{mM}$ for pyridoxal 5-phosphate (PLP), bathophenanthroline (BAT), Nethylmaleimide (NEM), butylmalonate (BMA), and phenylsuccinate (PHS); $0.3 \mathrm{mM}$ for bromocresol purple (BCP); $10 \mu \mathrm{M}$ for carboxyatractyloside (CAT) and bongkrekic acid 
(BKA), $20 \mu \mathrm{M}$ for $\alpha$-cyano-4-hydroxycinnamate $(\mathrm{CCN})$, and $0.2 \%$ for tannic acid (TAN). The extent of inhibition (percent) for each carrier from a representative experiment is reported. Similar results were obtained in at least three experiments. 


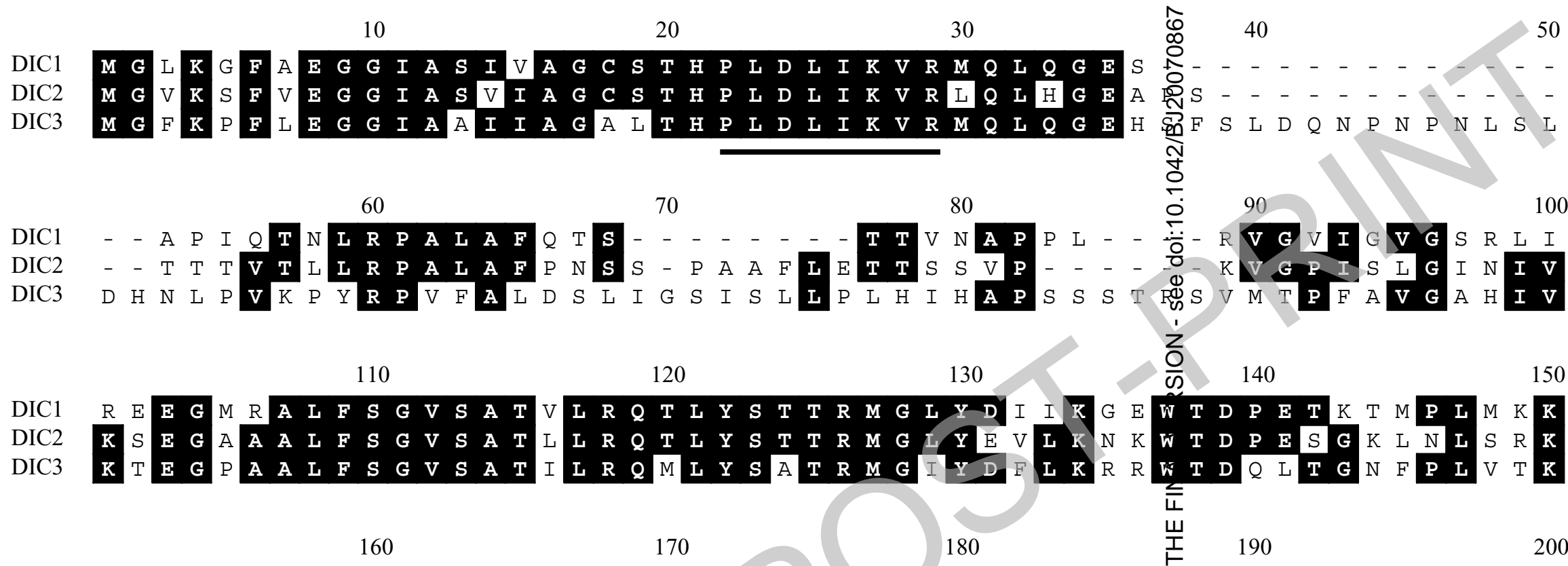

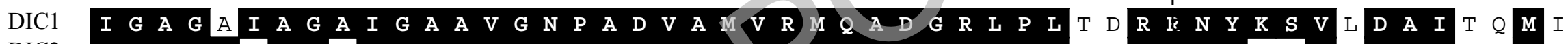

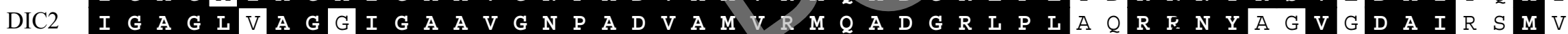

DIC3 I

$210 \quad 220 \quad 230 \quad 240 \quad 250$

DIC1 R G E G V T S L W R G S S I T I N R A M L V T S S Q L A S Y D S V K E T I L E DIC2 $\mathrm{K}$ G E E G V T S S L W R G S A L T I I R R A M I V T A A Q L L A S Y D D Q F

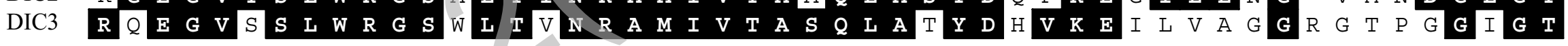

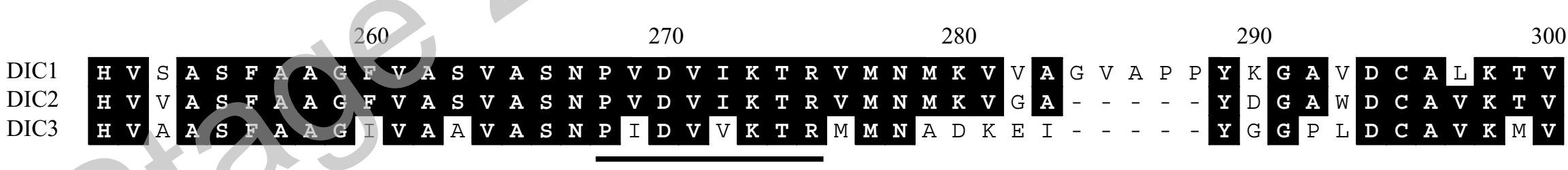

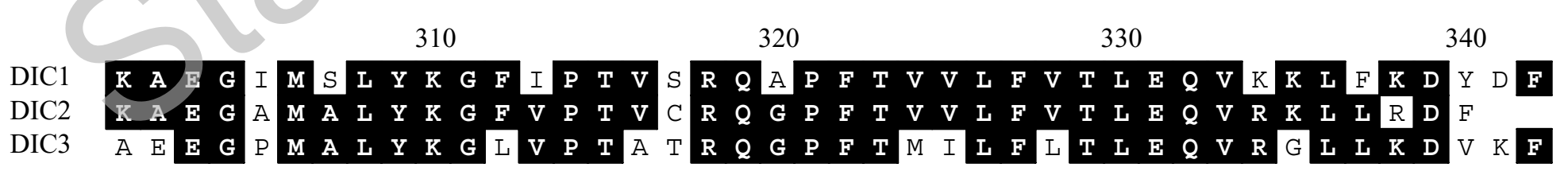




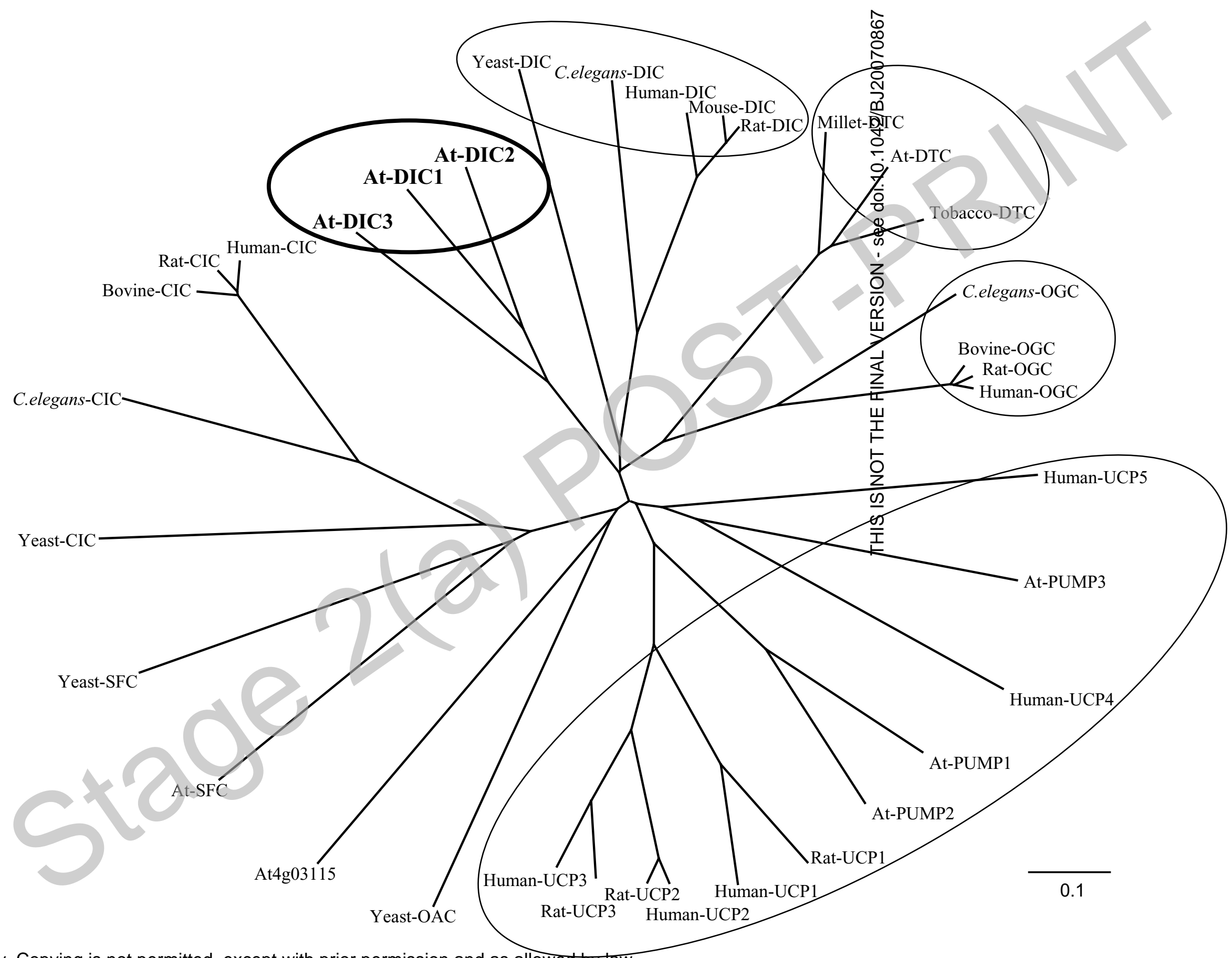

Licenced copy. Copying is not permitted, except with prior permission and as allowed by law. (c) 2007 The Authors Journal compilation (@ 2007 Biochemical Society 


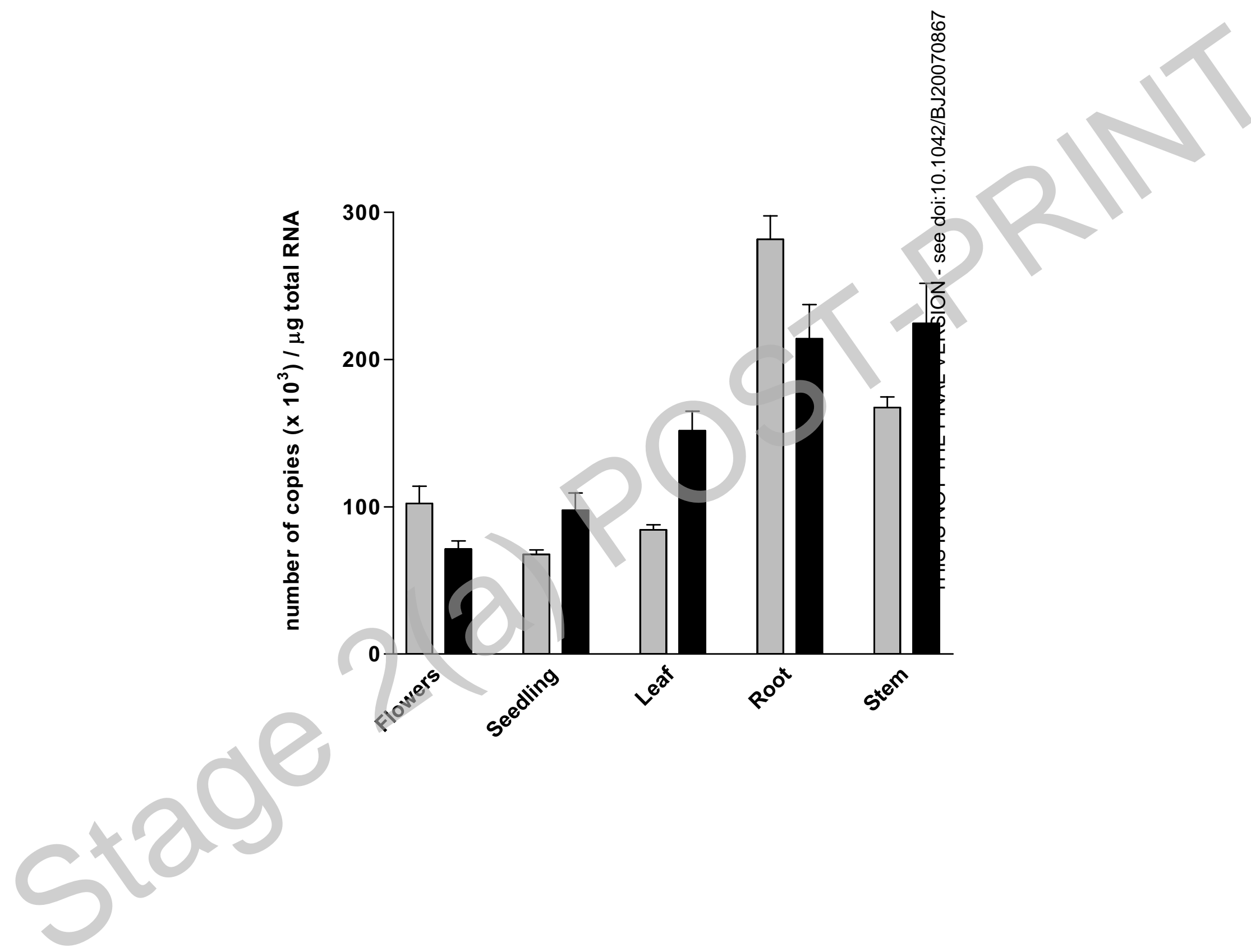




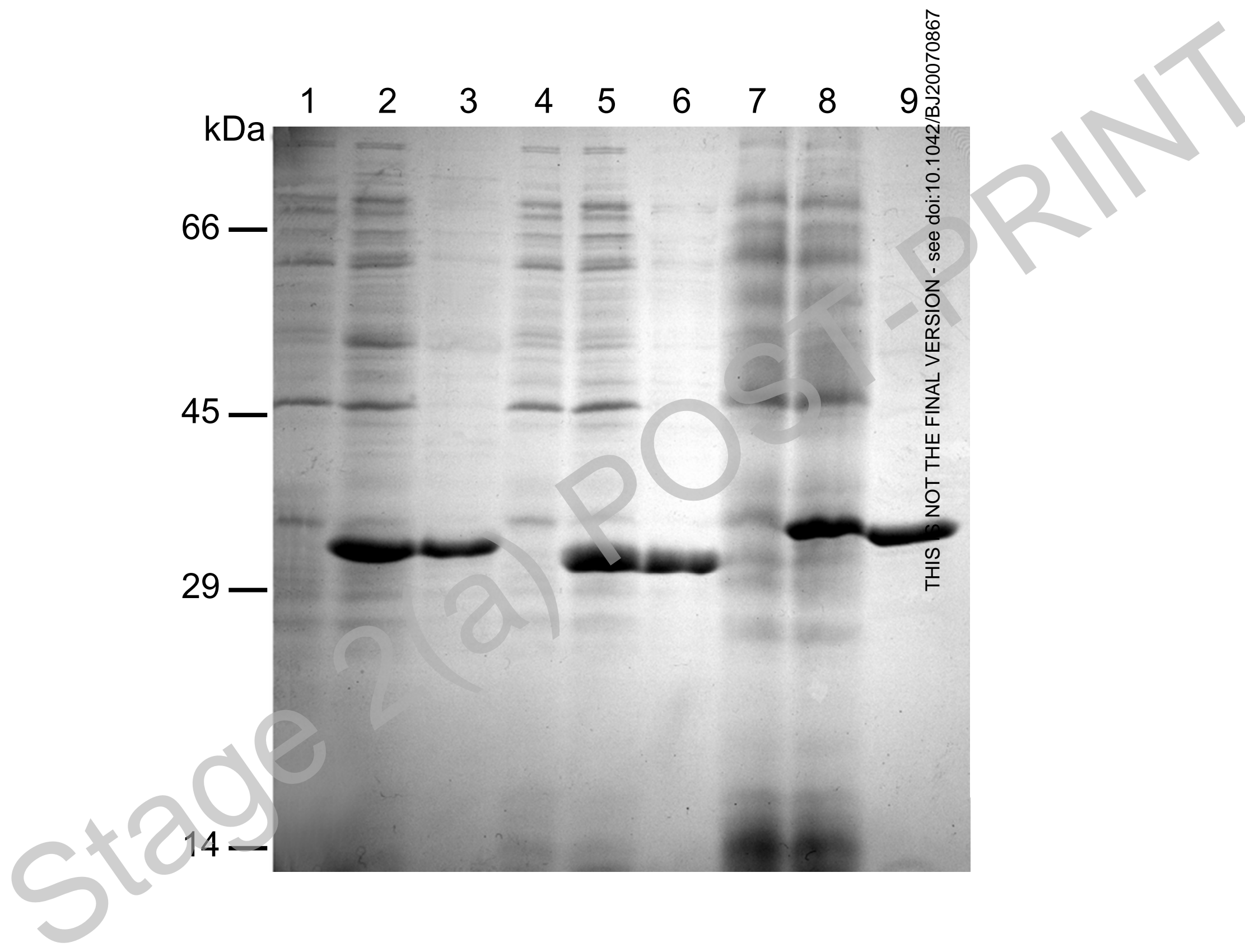




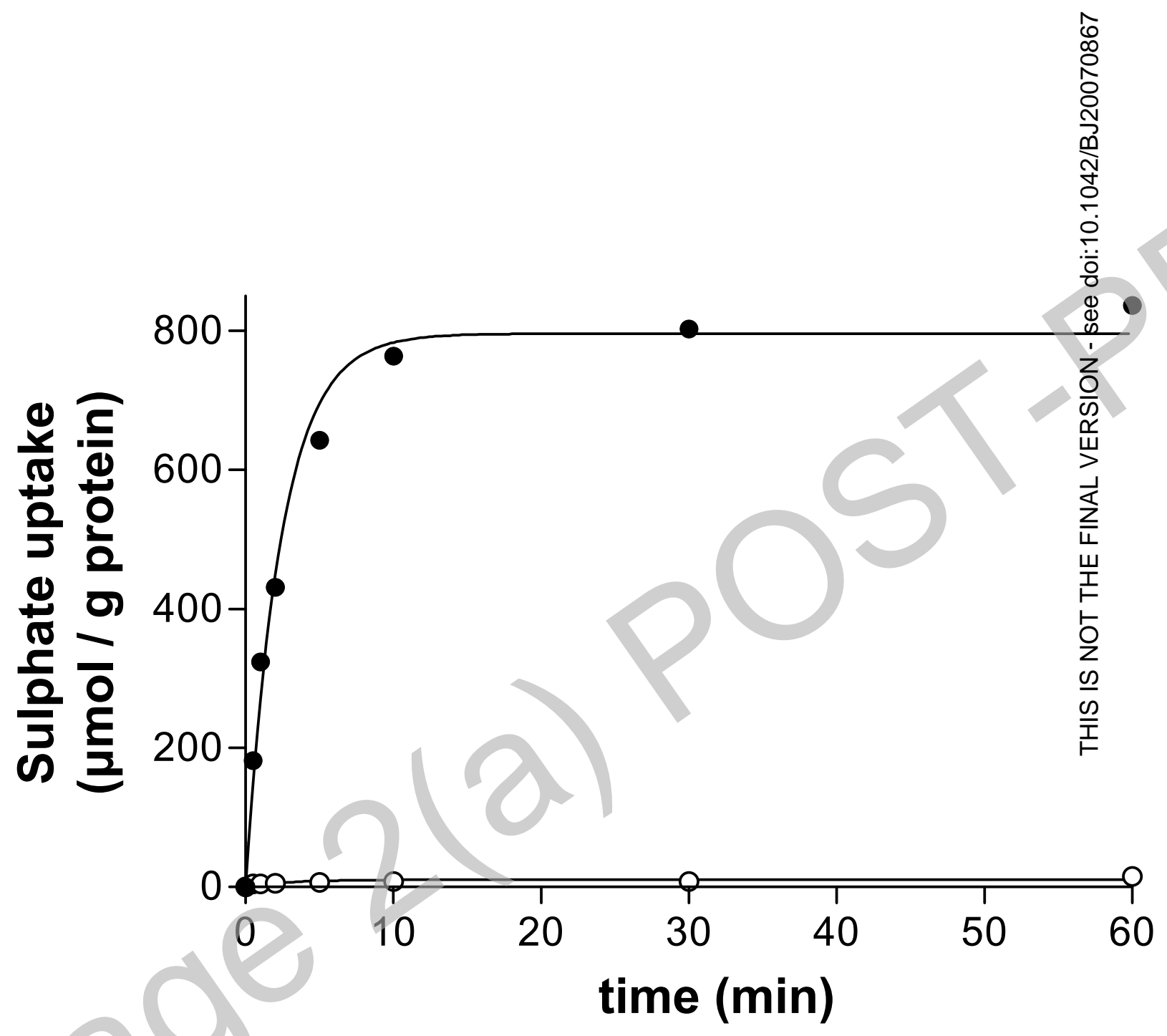




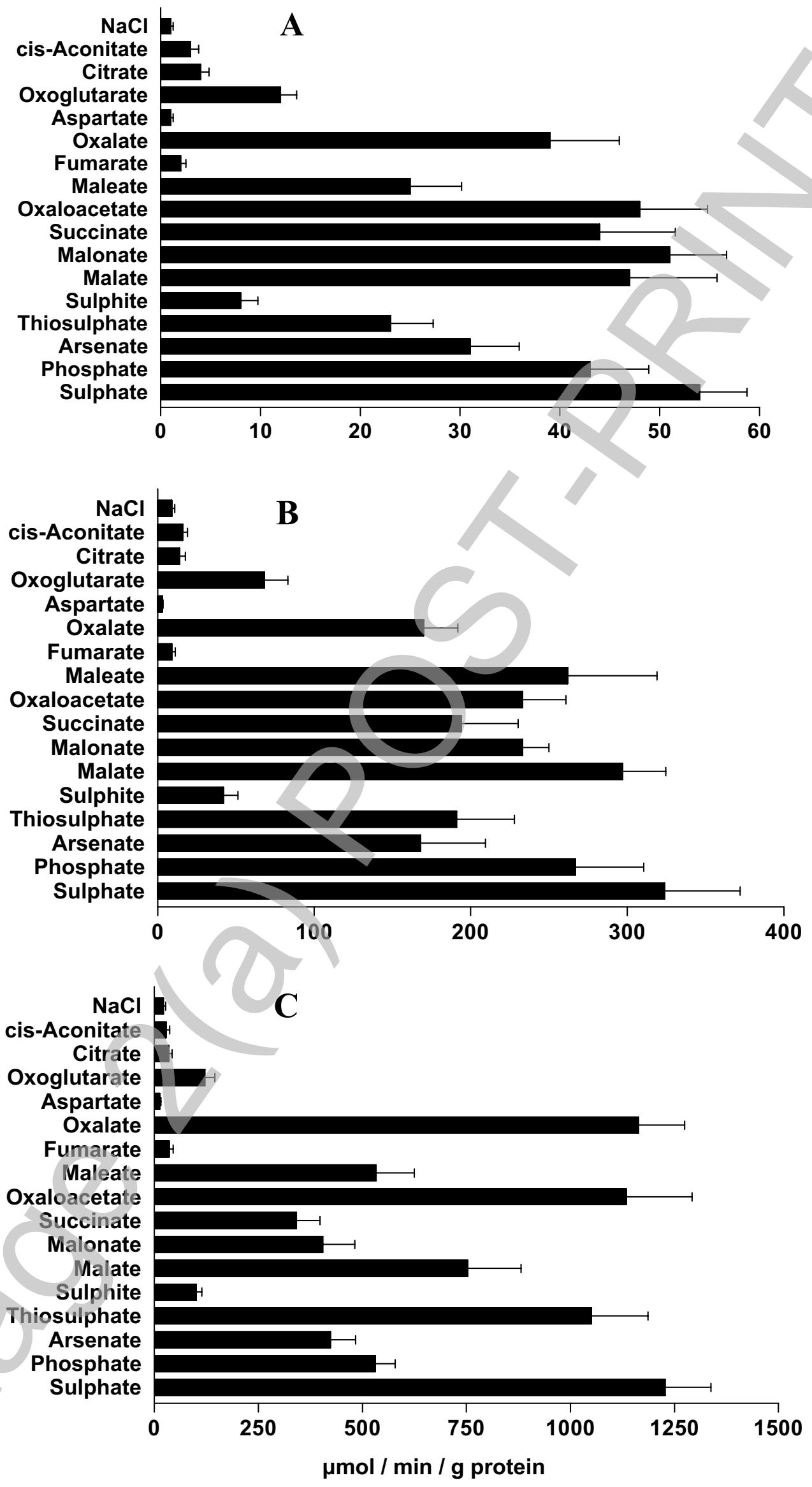

Licenced copy. Copying is not permitted, except with prior permission and as allowed by law. (C) 2007 The Authors Journal compilation (C) 2007 Biochemical Society 


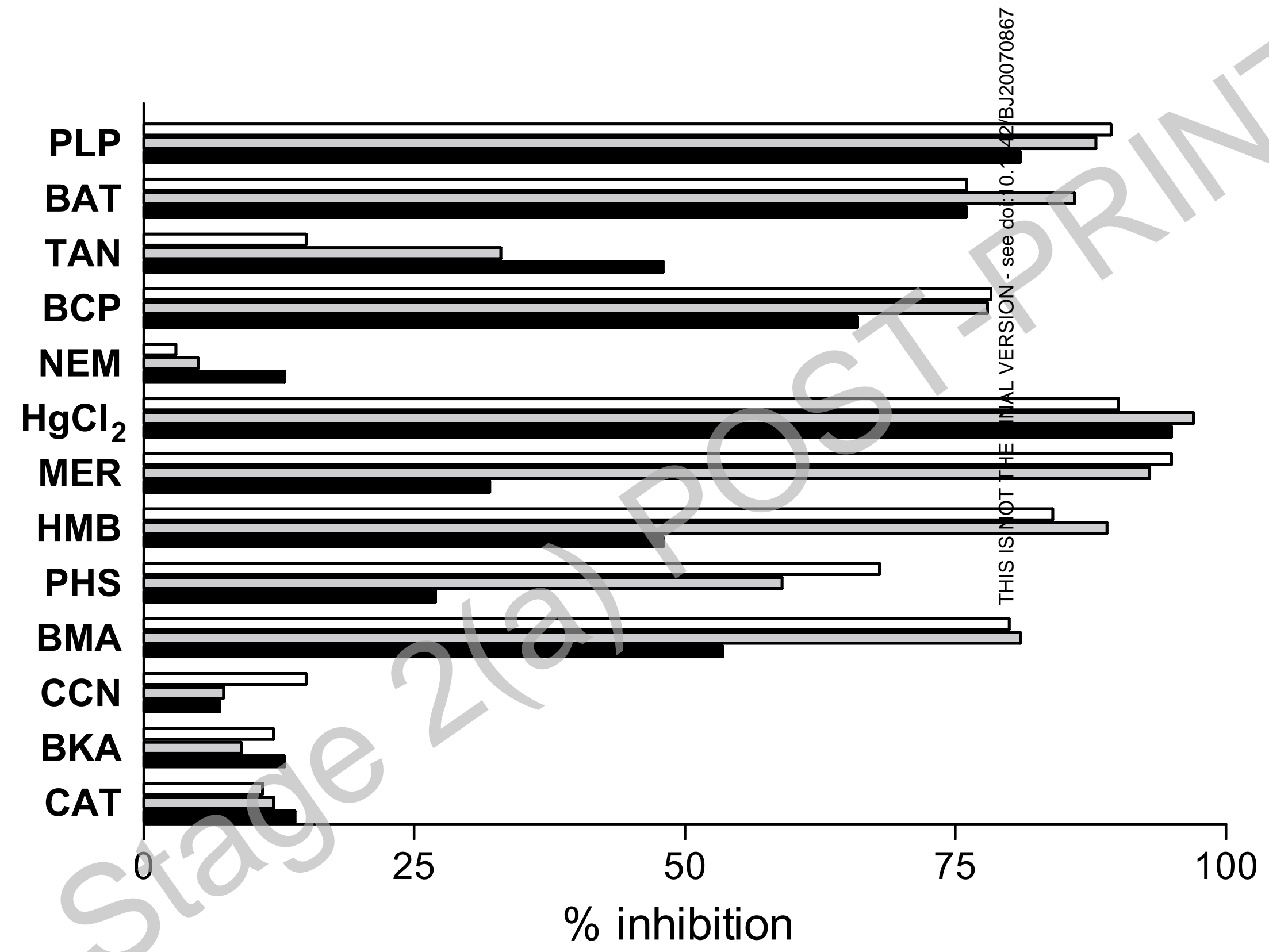

